\title{
A Meta-Analysis of Selected Studies on the Effectiveness of Gamification Method for Children
}

\author{
Muhibuddin Fadhli \\ Graduate School, State University of Malang, Malang, Indonesia, \\ muhib.fadhli@umpo.ac.id
}

Billy Brick

Coventry University, Coventry, United Kingdom, lsx133@ coventry.ac.uk

Punaji Setyosari

Graduate School, State University of Malang, Malang, Indonesia, punaji.setyosari.fip@um.ac.id

\section{Saida Ulfa}

Graduate School, State University of Malang, Malang, Indonesia, saida.ulfa@gmail.com

\section{Dedi Kuswandi}

Graduate School, State University of Malang, Malang, Indonesia, dedi.kuswandi.fip@um.ac.id

\begin{abstract}
A Meta-analysis of selected studies on the effectiveness of gamification method for children. Multiple gamification methods are used to motivate students to improve their learning outcomes. Yet, this method is still very rarely used in learning for children aged 6-10 years. This systematic review and meta-analysis aim to objectively determine the effectiveness of gamification method in increasing knowledge, skills and attitudes of children aged 6-10 years. The data were obtained from the ERIC, Emerald and Elsevier databases published between 2014-2018 using the keywords of "gamification on education", "gamification methods", and "children". In the chosen systematical analysis, 6 studies were then reviewed using a meta-analysis. The effect summary showed a value of 1.01 with confident interval of $0.98-1.05$, which indicates that gamification method is statistically effective in improving students' knowledge, skills, and children's attitudes. The Z test with a value of 0.68 and a significance level of $5 \%$ also showed a significant effect of this method calculated by random-effect models.
\end{abstract}

Keywords: meta-analysis, gamification, children, education, knowledge

Citation: Fadhli, M., Brick, B., Setyosari, P., Ulfa, S., \& Kuswandi, D. (2020). A Meta-Analysis of Selected Studies on the Effectiveness of Gamification Method for Children. International Journal of Instruction, 13(1), 845-854. https://doi.org/10.29333/iji.2020.13154a 


\section{INTRODUCTION}

Children and play go hand in hand. Play, as well as learning, are natural components of children's everyday lives. When children are asked what they like to do best, the answers are unanimous: to play (Samuelsson \& Carlsson, 2008). This means that they describe playing as well as learning as something joyful, as an activity or as something transgressive, that the two touched upon each other or run into each other and are transformed to each other.

One method to education that could be conducted is by involving technology, play and learning in a game. The term used in this article is gamification. "Kapp defines gamification with the following way gamification is using game-based mechanics, aesthetics, and game-thinking to engage people, motivate action, promote learning, and solve problems" (Kapp, 2012, p.10). It is argued that game can be more meaningful through design experience, Gee (2016) has explained that game design experience is experiences - in the real world or via media - that are designed to elicit specific effects or effects. One aspect of the game is rewarding, in so far that gamification is like a reward. In behaviourist theory, the reward reinforces behavior which is rewarding someone for particular behaviour encourages him to behave in the same way in a similar situation (Skinner, 1974). Reiners and Wood argue that Rewards have been used for centuries to change behavior; children and pets are trained through rewards and punishments, soldiers are rewarded for achievements through ranks and badges, and schools use grades to award students to do schoolwork (Reiners, \& Wood, 2015). Rewarding is one of the elements in a game that can be used to attract the attention of children so that they are involved in an activity.

This study of gamification as a method has been widely used. However, from the search results in the ERIC, Emerald, Elsevier database, this method is most widely applied in the age range of 12 years and above, Randel (1992), Wolfe (1997), Hay's (2005), Vogel (2006), Ke (2009), Sitzmann's (2011), Kusuma (2018).

The purpose of this study is to ascertain the effectiveness of the gamification method in teaching \& learning for 6-10 years olds and how it enables technology-savvy children to improve their knowledge because at this age children learn very quickly. Therefore, this article aims to know how much research has been done and what more needs to be done through meta-analysis within the following limitations: (a) studies where the gamification method was performed on children aged 6-10 old (b) where it was considered how gamification has had an effect on the development and growth of children.

In (1976) Glass introduced the use of an effective review method that could be used in the field of education. This method is called "meta-analysis". Meta-analysis is simply the statistical analysis of a large collection of data from individual studies for the purpose of integrating the findings.

Randel (1992) conducted a meta-analysis in the use of games and simulation in learning. Data were collected based on the use of gamification method in the classroom 
throughout 1991. It was found 68 studies using gamification method at the university level. This study contained the following findings:

1. The beneficial effects of games and simulations were most likely to be found when specific content was targeted and objectives precisely defined;

2. Games are rated as more interesting than conventional instruction;

3. Careful consideration needs to be given to the measures used to demonstrate the effects of games;

4. The experimental designs used to evaluate games need to be more rigorous.

Based on Randel's findings, this article aims to answer the following questions;

1. How does the typical study define gamifications?

2. What affordances does gamification offer to children between the ages of 6 to 10 years old.

\section{MATERIALS AND METHOD}

\section{Criteria of Inclusion}

Before conducting the study on how gamification affects children, two criteria in this analysis have been determined. First, the study must be based on empirical guidelines, involving the process of extracting data. Second, the subjects of the study must be children aged 6-10 years.

\section{Source of Data}

The first step in this meta-analysis is to collect studies of the effect of applying the gamification method to children aged 6-10 years. The authors used Prisma protocol in a review analysis. Keywords used for this data search are "gamification on education" "gamification methods" and "children" in the online databases, ERIC, Emerald, Elsevier. From the results of the search, we found more than 4,230 keywords and citations from 4020 authors as shown in Figure 1. As determined in the criteria of inclusion, only pre-post empirical studies, as well as quantitative analysis were included in this study. Reviews, editorial articles, commentaries, proposal opinions, and conference proceedings were excluded from this review. 


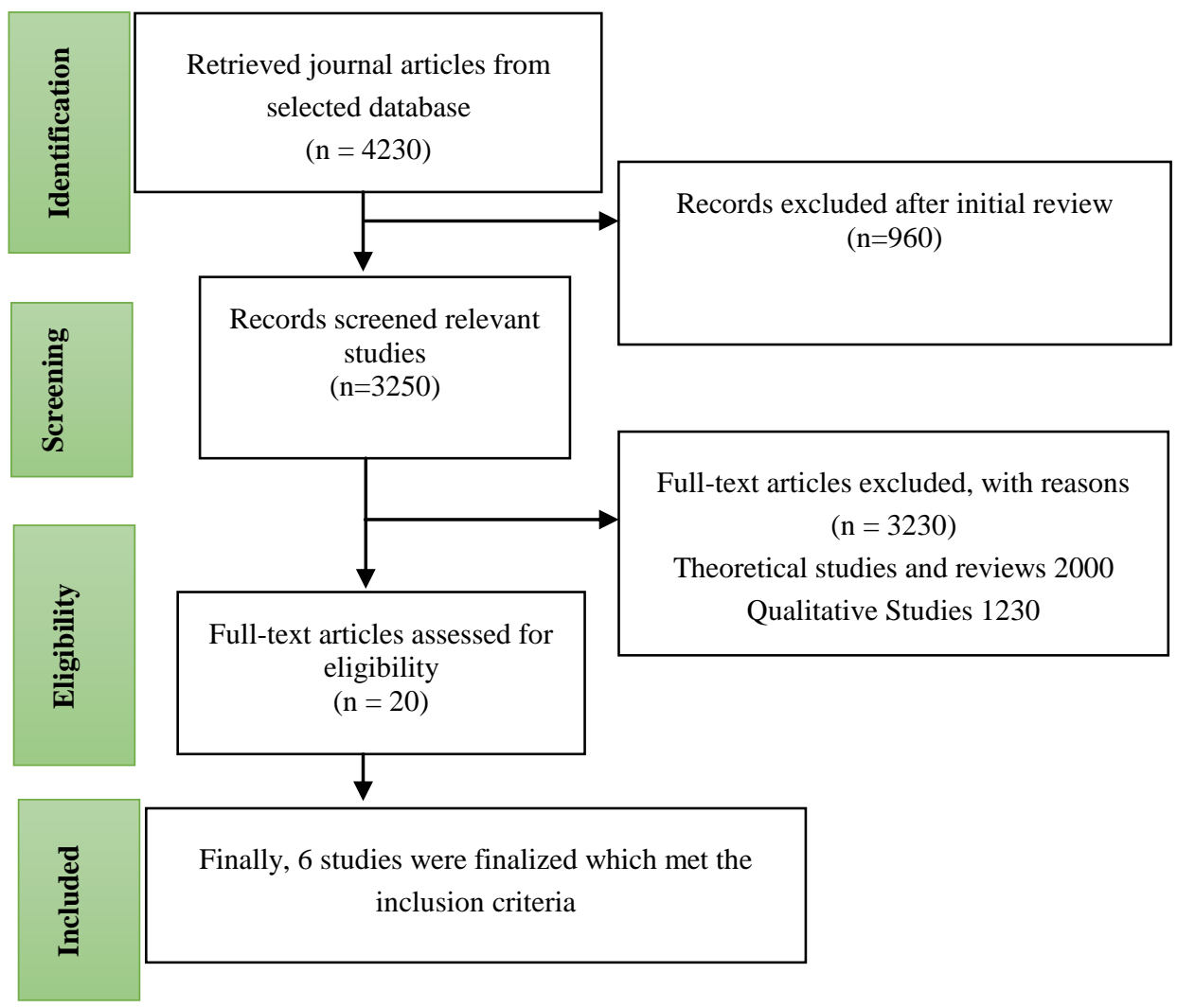

Figure 1

Flow Diagram Shows Step Wise Selection of Studies

\section{Quality Assurance}

In order to be included in this study two independent reviewers must have objectively reviewed selected studies in accordance with the inclusion criteria and keywords. The barriers and challenges in the articles included in the criteria must have been identified and agreed upon by both reviewers.

\section{Data Extraction}

During the data screening process, 3,250 studies were excluded because they did not meet the criteria that gamifications method was carried out at the age of 10 and above and there was a data duplication process. The method used in this process was to input all results of the study into the RefWorks database. Other 960 studies were excluded from the criteria because after reviewing the title, abstract and content did not meet the criteria. Practically only 20 studies were relevant to the criteria by which they have applied the experimental method to test the effectiveness of the gamification method for 
children. However, after conducting a full-text analysis of 20 studies, only 6 studies were found to be relevant to the criteria of this meta-analysis. The six studies that met the criteria in this meta-analysis were;

- Achievement Emotions and Peer Acceptance Get Together in Game Design at School (Brondino et al., 2014).

- Learning healthy lifestyles through active videogames, motor games and the gamification of educational activities. (González et al., 2016).

- Bacon Brains: Video Games for Teaching FOR Science of Addiction (Epstein et al., 2016).

- An Augmented Reality Game to support therapeutic Education for Children with Diabetes (Calle-Bustos et al., 2017).

- The effect of mobile gamification app on elementary students' Spanish achievement and self-efficacy (Rachels \& Rockinson-Szapkiw., 2018).

- Using game Technology to Teach Six Elementary School Children with Autism to Take a Shower Independently (Kang \& Chang., 2018).

\section{Statistical Analysis}

This meta-analysis uses a Forest plot that graphically illustrates the validity of the results of selected studies in a very effective way. The Forest plot is programmed through the Review Manager 5.3 application developed by the Cochrane Library (Guraya, 2016). In this plot, the effect size (ES) in each study was measured using the software. Q test was used to measure heterogeneity in each study. Heterogeneity is a value to determine how different the results obtained in each study included in the meta-analysis, a hypothesis (null hypothesis) is formulated as "all studies are equal (homogeneous)".

I squared $\left(\mathrm{I}^{2}\right)$ is a statistical test to measure heterogeneity. $\mathrm{I}^{2}$ values above $50 \%$ indicate considerable heterogeneity (Hippel, 2015). After analyzing heterogeneity, a Fixed Effect Model (FEM) is used for the heterogeneity test showing homogeneity. A Random Effect Model (REM) is used for heterogeneity test showing heterogeneity (Snijder et.al., 2012). The significance level in this study was $5 \%$ ( $p<0.05$ ). To assess bias from the six studies, a Funnel plot was used. A funnel plot is a graph that represents how much effect of the sample size of a study (axis y) has on the results of the publication (axis $\mathrm{x}$ ) (Jonathan et.al., 2004).

\section{FINDINGS}

The forest plot in Table 1. The result of forest plot below illustrates that confidence intervals were at the $95 \%$ level. Each study has an effect size indicated by a symbol of square and the level of trust indicated through a horizontal line. This plot also showed that there was a broad level of trust and different inconsistent response rates which indicated that there was a clear heterogeneity in this study. To confirm heterogeneity statistically as reviewed in statistical analysis, this study used a Q test, $\mathrm{I}^{2}$ and Tau2. The results of the forest plot in Table 1 show that $\mathrm{Q}\left(\mathrm{Chi}^{2}=10.58\right)$ with a significance level 
of $5 \%$ indicates that the null hypothesis is rejected which means that the data was heterogeneous.

$\mathrm{I}^{2}$ values of $53 \%$ were categorized as data from the six studies above including heterogeneous moderate categories. Based on the results of the Cochrane $\mathrm{Q}$ and $\mathrm{I}^{2}$, the random effect model is more suitable to be used in this study. A summary of the effects of each study is described in the symbol (diamond) which has a standardized mean difference (SMD) of 1.01 with confidence intervals of 0.98-1.05. These findings confirm that the effects of gamification method for children aged 6-10 years exceed the criteria suggested by Cohen, which is 0.8 (Cohen. 1988). This shows that 6 studies of gamification method that have been conducted have a positive impact on children. The $\mathrm{Z}$ test with a value of 0.68 with a significance level of $5 \%$ indicated that gamification method also has a positive impact on the child using the random-effects model.

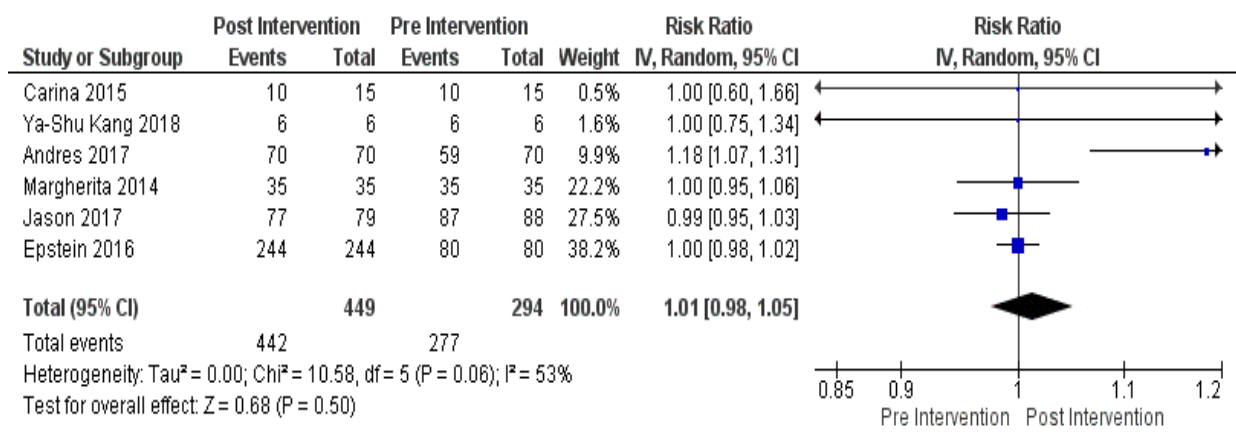

Figure 2

The Result of Forest Plot Shows Effect Summary from Selected Studies

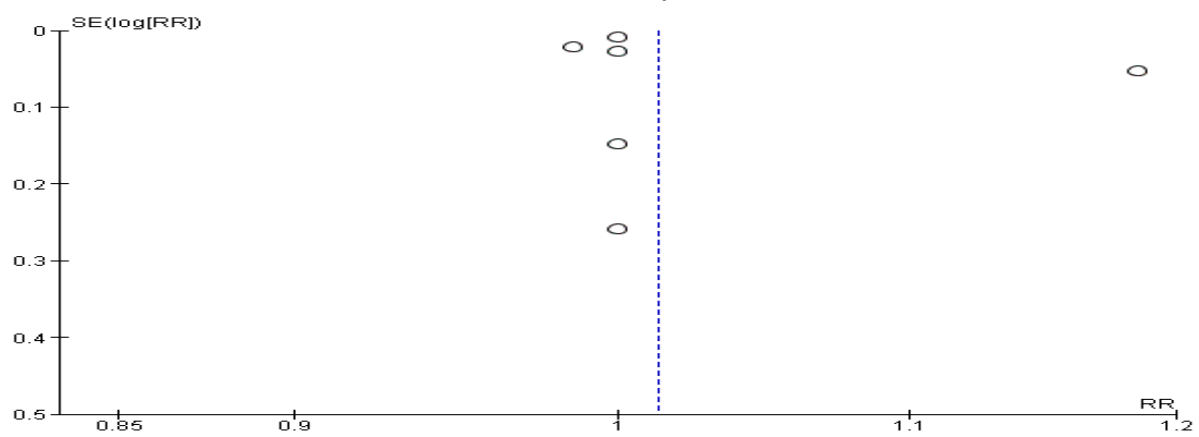

Figure 3

The Result of Funnel Plot Shows the Bias of Publication

To assess the bias of these six studies, a funnel plot was used with the following results: To find the bias of this study, it can be seen in Figure 2 that the data were spread evenly. Therefore, it is concluded that there is no bias in this publication. 


\section{DISCUSSION}

Gamification method with the aim of increasing the learning process has a positive impact on increasing students' motivation and behavior (Hamari, Koivisto \& Sarsa 2014). Also, this method can be the role of technology that could bring human to civilization in the 21st century (Wangi et.al., 2018). The findings in the systematical review above indicated that the gamification method in their 24 studies that have been conducted positively effects motivational affordances, psychological and behavioral outcomes. The findings are supported by research on the effects of the gamification method to support psychological aspects and motivation in task completion. This research was conducted with path analysis which shows that game-elements can motivate learner to solve a learning task (Brondino et al., 2014). The gamification method can also be used in all forms of topography and demographic forms. This method is however confirmed by Lamrani et al. (2018) who conducted his research in rural Africa. They observed how gamification method can improve several aspects such as mathematics, language, social, and even health.

Furthermore, in the health sector there are several findings that show that gamification has positive affects in tackling obesity. Therefore, the gamification method can also be empirically proven to make children conditioned, especially to control their appetite (Gonzalez et al., 2015). Besides this, the gamification method can also be used to prevent children from diabetes. This study applied virtual reality games to recognize foods that trigger the risk of diabetes and therefore in the real-world children can recognize which foods are healthy (Calle-Bustos et al., 2017). Kostenius, Hallberg \& Lindqvist also argues that the gamification method can be used as a media for health promotion (Kostenius et al., 2018).

In language learning, some research has shown that gamification has also shown empirically to positively improve their abilities in language learning. As stated by Rachels \& Rockinson-Szapkiw (2018), the research conducted used gamification as the method in learning Spanish for age from seven to ten old. This study took 12 weeks with two classes namely control and experimentation. This demonstrates that Duolingo ${ }^{\circledR}$ is a useful tool for teaching Spanish to elementary students. Charitonos et al (2016) on their initial project have described the using of ImparApp to teach Italian Language was positively perceived by a group of students, as it allowed them to experience their course's content in a new and playful way. Gamification method can also be used not only on language recognition for normal children. The research conducted by Liu et al. (2015) has proven that this method can be used to improve the ability of children with disabilities (deaf) interested in participating in speech training systems.

\section{STUDY LIMITATIONS}

In this systematic review and meta-analysis, this study has the limitation of finding insufficient number of studies in gamification. The limitations of the study are reflected by the heterogeneity of each study because of the limited amount research on the use of gamification 6-10 year-olds. This can be seen in Table 1. In addition, the study reported in this article is the effectiveness of gamification method for children aged 6-10 years in 
the pre-test and post-test design. Future studies such as randomized controlled effect may shed light on providing more objective analysis by determining student's learning outcomes.

\section{CONCLUSION}

This study has identified the positive outcomes of gamification method for children aged 6-10 years in various disciplines, and other aspects of development. The effectiveness of post-test design shows that gamification method can improve children's cognitive, skills, attitude, language, health, and social-emotional abilities. In general, the results of this meta-analysis indicate that gamification has a positive effect on children's learning outcomes. These results are general to all aspect of children's learing outcomes. More research is required to determine the effectiveness of gamification on each aspect. Moreover, there are several studies that require further research, whether the effects caused are really from gamification method or other factors.

\section{FUNDING SOURCE}

This article is supported by Enhancing International Publication Program and Indonesia Endowment Fund for Education Scholarship (BUDI-DN), collaboration between the Ministry of Research, Technology and Higher Education with the Finance Ministry of the Republic of Indonesia. With the research grant number of 20161141081928.

\section{REFERENCES}

Brondino, M., Dodero, G., Gennari, R., Melonio, A., Raccanello, D., \& Torello, S. (2014). Achievement emotions and peer acceptance get together in game design at school. ADCAIJ: Advances in Distributed Computing and Artificial Intelligence Journal, 3(4), 1-12. doi:10.14201/ADCAIJ201434112.

Calle-Bustos, A., Juan, M., García-García, I., \& Abad, F. (2017). An augmented reality game to support therapeutic education for children with diabetes. PLOS ONE, 12(9) doi:10.1371/journal.pone.0184645.

Charitonos, K., Morini, L., Arnab, S., Cervi-Wilson, T., \& Brick, B. (2016). Urban explorations for language learning: a gamified approach to teaching Italian in a university context. CALL communities and culture-short papers from EUROCALL, 9499.

Cohen, Jacob. (1988). Statistical power ANALYSIS for the behavioral sciences. SERBIULA (sistema Librum 2.0). 2nd. https://doi.org/10.1016/B978-0-12-1790608.50012-8.

Davis-Kean, P. E. (2005). The influence of parent education and family income on child achievement: the indirect role of parental expectations and the home environment. Journal of Family Psychology, 19(2), 294.

Epstein, J., Noel, J., Finnegan, M., \& Watkins, K. (2016). Bacon brains: Video games for teaching the science of addiction. Journal of child \& adolescent substance abuse, 25(6), 504-515. https://doi.org/10.1080/1067828X.2015.1103348. 
Glass, G. V. (1976). Primary, secondary, and meta-analysis of research. Educational Researcher, 5(10), 3-8. https://doi.org/10.3102/0013189X005010003.

Gee, J. (2016). Video games, design, and aesthetic experience. Rivista di estetica, (63), 149-160. doi:10.4000/estetica.1312.

González, C. S., Gómez, N., Navarro, V., Cairós, M., Quirce, C., Toledo, P., \& Marrero-Gordillo, N. (2016). Learning healthy lifestyles through active videogames, motor games and the gamification of educational activities. doi://doi.org/10.1016/j.chb.2015.08.052.

Guraya S. Y., Guraya S. S., Almaramhy H. H. (2016). The legacy of teaching medical professionalism for promoting professional practice: A systematic review. Biomed Pharmacol J, 9, 809-817. http://dx.doi.org/10.13005/bpj/1007.

Hamari, J., Koivisto, J., \& Sarsa, H. (2014). Does gamification work? - A literature review of empirical studies on gamification. In Proceedings of the 47th Annual Hawaii International Conference on System Sciences, HICSS 2014 (pp. 3025-3034). [6758978] IEEE Computer Society Press. doi: 10.1109/HICSS.2014.377.

Hays, R. T. (2005). The effectiveness of instructional games: A literature review and discussion (Report No: FL 32826-3275). Naval Air warfare Center Training Systems Division. Retrieved from: https://apps.dtic.mil/dtic/tr/fulltext/u2/a441935.pdf.

Rachels, J. R., \& Rockinson-Szapkiw, A. (2018). The effects of a mobile gamification app on elementary students' Spanish achievement and self-efficacy. Computer Assisted Language Learning, 31(1-2), 72-89. doi:10.1080/09588221.2017.1382536.

Sterne, J. A. C., \& Harbord, R. M. (2004). Funnel plots in meta-analysis. Stata Journal, 4(2), 127-141.

Kang, Y., \& Chang, Y. (2018). Using game technology to teach six elementary school children with autism to take a shower independently. Developmental Neurorehabilitation, 1-9. doi:10.1080/17518423.2018.1501778.

Kapp, K. M., (2012). The gamification of learning and instruction: Game-based methods and strategies for training and education. Pfeiffer; San Francisco, CA.

Ke, F. (2009). A qualitative meta-analysis of computer games as learning tools. In R.E. Ferdig (Ed), Effective electronic gaming in education (pp. 1-32). Hershey, PA: Information Science Reference.

Kusuma, G. P., Wigati, E. K., Utomo, Y., \& Putera Suryapranata, L. K. (2018). Analysis of gamification models in education using MDA framework. doi://doi.org/10.1016/j.procs.2018.08.187.

Kostenius, C., Hallberg, J., \& Lindqvist, A. (2018). Gamification of health education: Schoolchildren's participation in the development of a serious game to promote health and learning. Health Education, 118(4), 354-368. doi:10.1108/HE-10-2017-0055. 
Lamrani, R., Abdelwahed, El H., Chraibi, S., Qassimi, S., \& Hafidi, M. (2018). Gamification and serious games based learning for early childhood in rural areas: MEDI 2018 International Workshops, DETECT, MEDI4SG, IWCFS, REMEDY, Marrakesh, Morocco, Proceedings. 79-90. doi:10.1007/978-3-030-02852-7_7.

Liu, Q., Cai, F., Yang, Y., \& Han, T. (2015). Gamification design-based research on speech training system for hearing-impaired children. Paper presented at the Engineering Psychology and Cognitive Ergonomics, 140-151.

Moher, D., Liberati, A., Tetzlaff, J, \& Altman, D. G. (2009). Preferred reporting items for systematic reviews and meta-analyses: The PRISMA statement. PLoS Med 6(7), e1000097. doi:10.1371/journal.pmed1000097.

Wangi, N. B. S., Setyosari, P., Kuswandi, D., \& Dwiyogo, W. D. (2018). Gamification as a strategy to improve student learning motivation: Preparing student for 21 st century. International Journal of Engineering and Technology, 7, 323-325.

Paul T. von H. (2015). The heterogeneity statistic I(2) can be biased in small metaanalyses. BMC Medical Research Methodology, 15, 35. doi:10.1186/s12874-015-0024$\mathrm{Z}$.

Randel, J. M., Morris, B. A., Wetzel, C. D., \& Whitehill, B. V. (1992). The effectiveness of games for educational purposes: A review of recent research. Simulation \& Gaming, 23(3), 261-276.

Samuelsson, I. P., \& Carlsson, M. A. (2008). The playing learning child: Towards a pedagogy of early childhood. Scandinavian Journal of Educational Research, 52(6), 623-641. doi:10.1080/00313830802497265.

Skinner, B. F. (1974). About behaviorism. New York: Knopf.

Sitzmann, T. (2011). A meta-analytic examination of the instructional effectiveness of computer-based simulation games. Personal Psychology, 64(2).

Snijders, T. A. B, \& Bosker, R. J. (2012). Multilevel analysis: An introduction to basic and advanced multilevel modeling. Los Angeles: SAGE.

Reiners, T., \& Wood, L. C. (2015). Game cation in education and business. Springer Science.

Vogel, J. J., Vogel, D. S., Cannon-Bowers, J., Bowers, C. A., Muse, K., \& Wright, M. (2006). Computer gaming and interactive simulations for learning: A meta-analysis. Journal of Educational Computing Research, 34(3), 229-243.

Wolfe, J. (1997). The effectiveness of business games in strategic management course work. Simulation \& Gaming, 28(4). 360-376. 